\title{
Prolonged Hyperbilirubinemia after Contrast Use in a 16-Year-Old Boy with Gilbert's Syndrome: A Case Report and Literature Review
}

\author{
Woochul Shin', Suk Pyo Shin², Sang Hak Han³, Jung Kyung Yoo' \\ Departments of ${ }^{\top}$ Pediatrics, ${ }^{2}$ Internal Medicine, ${ }^{3}$ Pathology, Chuncheon Sacred Hopspital, Hallym University College of Medicine, Chuncheon, \\ Korea
}

This paper reports a child with Gilbert's syndrome who underwent cholecystectomy and endoscopic retrograde cholangiopancreatography, magnetic resonance cholangiopancreaticography to removal of the gallstones, then experienced increase in bilirubin of unknown cause.

Korean J Pancreas Biliary Tract 2021;26(3):200-204

Keywords: Contrast media; Gilbert disease; Hyperbilirubinemia; Gallstones; Pediatrics

\author{
Received Oct. 2, 2020 \\ Accepted Jul. 16, 2021
}

Corresponding author : Jung Kyung Yoo Department of Pediatrics, Chuncheon Sacred Hopspital, Hallym University College of Medicine, 77 Sakju-ro, Chuncheon 24253, Korea

Tel. +82-33-240-5169 Fax. +82-33-240-5000

E-mail; himurayakdol@hanmail.net

ORCID: https://orcid.org/0000-0002-7389-7678

This is an Open Access article distributed under the terms of the Creative Commons Attribution Non-Commercial License (http:// creativecommons.org/licenses/by-nc/3.0/) which permits unrestricted non-commercial use, distribution, and reproduction in any medium, provided the original work is properly cited.

Copyright $@ 2021$ by The Korean Journal of Pancreas and Biliary Tract

\section{INTRODUCTION}

Gilbert's syndrome (GS) is a liver disorder due to a mutation in the UGT1A1 gene which results in decreased activity of the bilirubin uridine diphosphate glucuronosyltransferase (UGT1A1) enzyme. It is typically inherited in an autosomal recessive pattern and occasionally in an autosomal dominant pattern depending on the type of mutation. It results in mild elevated levels of unconjugated bilirubin, typically less than $10 \mathrm{mg} / \mathrm{dL}$. Most cases of GS are detected due to mild hyperbilirubinemia found by change during a blood examination. ${ }^{1}$ And there is increased risk for cholelithiasis in patient with GS. ${ }^{2}$ Endoscopic retrograde cholangiopancreatography (ERCP) and magnetic resonance cholangiopancreaticography (MRCP) are diagnostic tools for the cholelithiasis, and the major complications of ERCP are acute pancreatitis, sepsis, bleeding and perforation. Prolonged post ERCP jaundice has been reported as a rare complication due to the toxicity of contrast agent, and a few cases are known in children. ${ }^{2}$ We report a case of GS patient prolonged hyperbilirubinemia after gallstone removal due to ERCP and MRCP from the contrast agent gadoterate and iopromide. 


\section{CASE}

A 15-year-old boy visited emergency room at Chuncheon Sacred Heart Hospital presented with intermittent upper abdominal pain, nausea and aggravating yellowish skin color for 4 days. In his past history, 10 years ago he was diagnosed with GS from UGT1A1 gene mutation in other hospital. And he had no history of recurrent conjugated hyperbilirubinemia. His father was also diagnosed GS and had a history of cholecystectomy due to gallstone. Before the onset of the disease, the patient did not take any medications or alcohol. In physical examination, yellowish skin color was seen in whole body in whole body was seen, and abdominal tenderness was noted in right upper quadrant and epigastric area. His vital sign was as follows: blood pressure 120/80 $\mathrm{mmHg}$, heart rate 70 /minute, respiratory rate 20 /minute, body temperature $36.7^{\circ} \mathrm{C}$.

On the day the patient admitted to Chuncheon Sacred Heart Hospital, complete blood count results at the onset of disease were as follows: white blood cell 4,930/uL, hemoglobin $13.7 \mathrm{~g} / \mathrm{dL}$, hematocrit 36.4\%, platelet count 194,000/uL. The liver test results were as follows: alanine aminotransferase (AST) 99 IU/L, alanine aminotransferase (ALT) $160 \mathrm{IU} / \mathrm{L}$, total bilirubin (TB) 28.23 $\mathrm{mg} / \mathrm{dL}$, direct bilirubin (DB) $14.33 \mathrm{mg} / \mathrm{dL}$, alkaline phosphatase

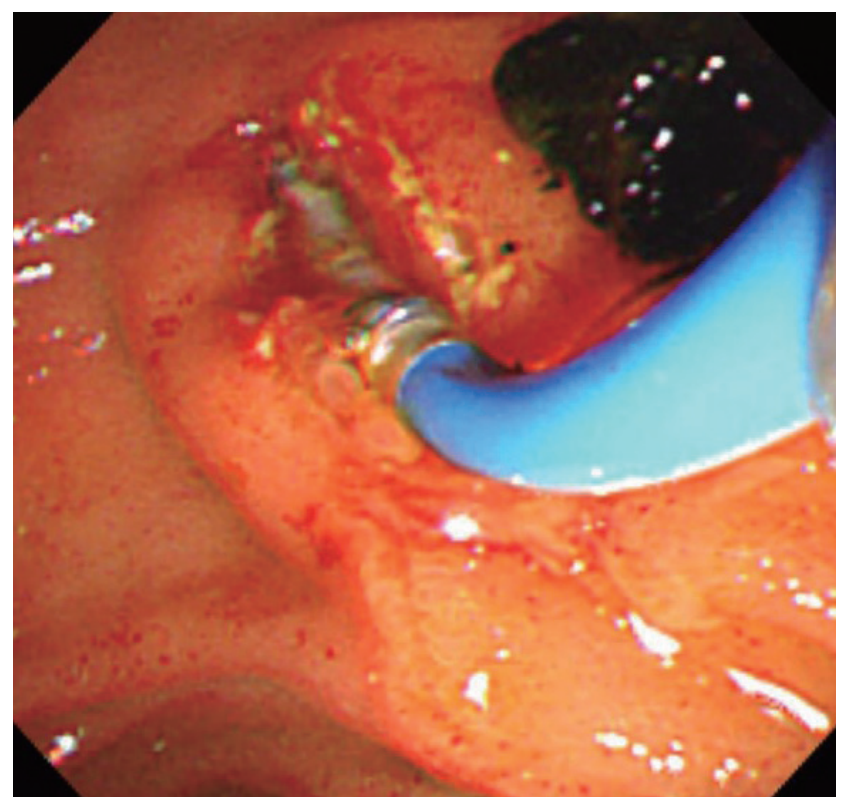

Fig. 1. Sludges and stones were retrieved with balloon sweeping with ERCP. ERCP, Endoscopic retrograde cholangiopancreatography.
(ALP) $172 \mathrm{IU} / \mathrm{L}$, and gamma-glutamyl transpeptidase $131 \mathrm{IU} / \mathrm{L}$. The patient's ferritin level was normal, and inflammatory markers were normal. The markers of viral infection for hepatitis A, B and $\mathrm{C}$ and other viruses (cytomegalovirus, Epstein-Barr virus) were all negative. Serum ceruloplasmin, ammonia, bile acid and alphafetoprotein levels were normal. Immunological tests for antinuclear antibody, anti-smooth muscle antibody, anti-mitochondrial antibody, anti-liver kidney microsomal antigen were also negative. Immunoglobulin G4 levels were normal. Abdominal ultrasonography showed the presence of cholecystitis with gallbladder sludge and multiple stones. Intravenous fluid administration with fat soluble vitamin supplement, ursodeoxycholic acid (UDCA) treatment was done at a dose of $200 \mathrm{mg} 3$ times daily. The second day after he admitted to Chuncheon Sacred Heart Hospital, his body temperature was increased up to $38.5^{\circ} \mathrm{C}$, and serologic inflammatory markers were elevated. His TB level showed slightly decreasing from 28.23 $\mathrm{mg} / \mathrm{dL}$ to $27.54 \mathrm{mg} / \mathrm{dL}$. So emergent cholecystectomy was delayed and empirical intravenous antibiotics were added (piperacillin/ tazobactam 3 g per 6 hours, metronidazole 1 g per 6 hours). MRCP showed multiple tiny stones in distal CBD, so the patient underwent emergent ERCP to remove that stone. In ERCP findings, ampulla was mildly prominent, and 4-5 mm sized filling defects were suspicious in distal part of midly dilated CBD. So endoscopic shincterotomy (EST) was performed, sludges and two $4 \mathrm{~mm}$ sized black pigmented stones were retrieved with balloon

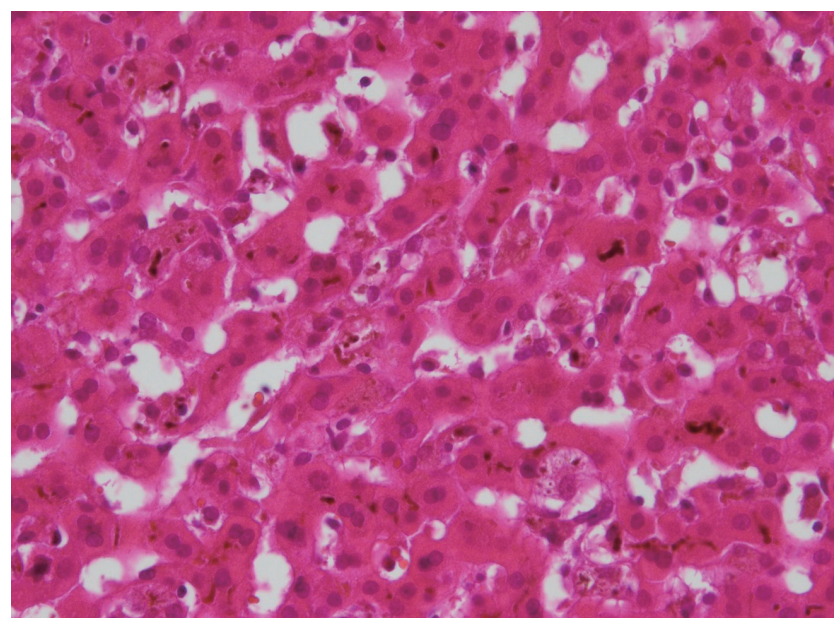

Fig. 2. Liver bile duct cholestasis with slight inflammation (Hematoxylineosin stain, original magnification $\times 400$ ). 
sweeping. And endoscopic biliary nasal drainage was done (Fig. 1).

The 3rd day after he presented to Chuncheon Sacred Heart Hospital, he complaint persistent upper abdominal pain and nausea, and skin color was yellowish in whole body yet. His TB level showed slightly increasing from $27.54 \mathrm{mg} / \mathrm{dL}$ to $31.6 \mathrm{mg} / \mathrm{dL}$ and the DB level $18.97 \mathrm{mg} / \mathrm{dL}$ to $22.75 \mathrm{mg} / \mathrm{dL}$. After the day, his TB level has increased continuously for 4 days, and laparoscopic cholecystectomy was performed after four days (the 7th day). But after cholecystectomy, his TB levels showed increasing pattern,

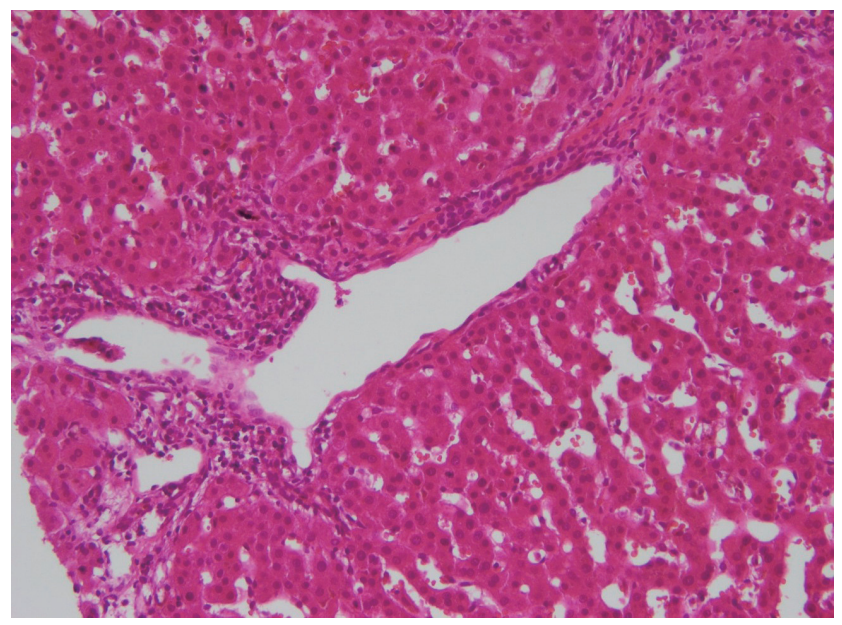

Fig. 3. Periportal minimal inflammation without fibrosis (Hematoxylineosin stain, original magnification $\times 200$ ). from $31.6 \mathrm{mg} / \mathrm{dL}$ to $34.62 \mathrm{mg} / \mathrm{dL}$ and the DB level $22.75 \mathrm{mg} / \mathrm{dL}$ to $28.08 \mathrm{mg} / \mathrm{dL}$. He underwent post-EST tubography, ERCP and follow-up ultrasonography to exclude any possibility of remaining choledocholithiasis. These studies did not show any positive findings.

A liver biopsy showed marked cholestasis with periportal minimal inflammation without evidence of fibrosis, bile duct paucity and interphase hepatitis (Fig. 2). After percutaneous liver biopsy, follow up sonographic findings showed right subhepatic (approximately $10 \times 1.5 \times 8.2 \mathrm{~cm}$ ) and pelvic fluid collections, but there were no evidence of acute complications such as bleeding (Figs. 2, 3).

On the basis of the fact that other causes of hyperbilirubinemia were ruled out except GS and instances of markedly increased bilirubin occurred after ERCP, MRCP and tubography, we thought the use of the contrast agents were suspected to be the cause of the prolonged hyperbilirubinemia. The patient kept intravenous fluid hydration, fat soluble vitamin supplement, UDCA (200 mg 3 times daily), prednisolone (30 mg daily), and cholestyramine ( $4 \mathrm{~g} 3$ times daily) for treatment. In addition, with the worsening of cholestasis, nasal biliary drainage was performed. With this conservative treatment, the bilirubin levels declined slowly and oral prednisolone was tapered regularly, the patient was

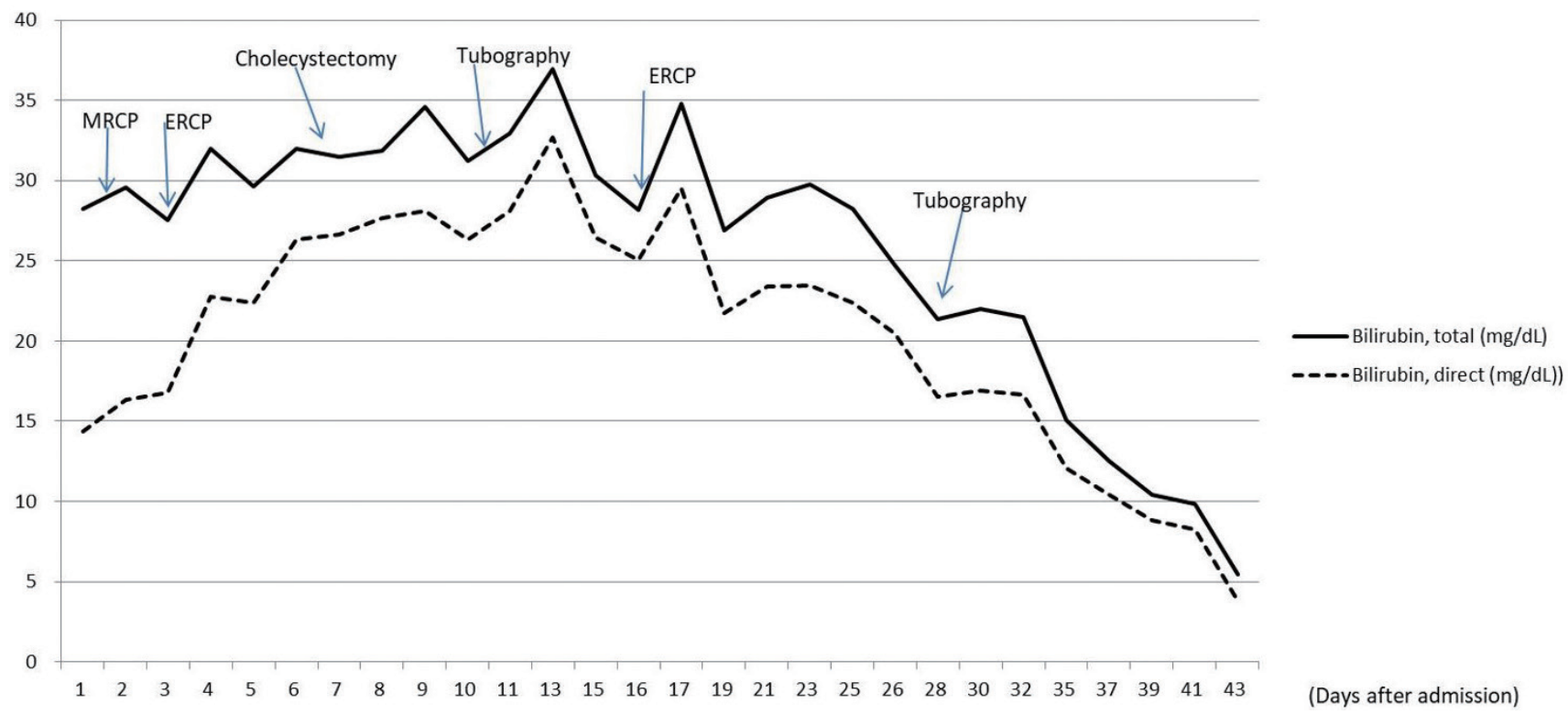

Fig. 4. The serum bilirubin levels from onset to the end of the follow up. MRCP, magnetic resonance cholangiopancreatography; ERCP, endoscopic retrograde cholangiopancreatography. 
discharged after 41 days. At his 6 months follow up visit, the serum bilirubin was nearly normal level and UDCA was discontinued (Fig. 4).

\section{DISCUSSION}

This paper reports a child with GS who underwent cholecystectomy and ERCP to removal of the gallstones, then experienced increase in bilirubin of unknown cause. In initial sonographic finding, multiple gallstones were seen, so cholecystectomy and ERCP were done to remove the gallstones. And to follow the decreasing TB level, repetitive ERCP, MRCP and several serologic, radiologic work up were performed to exclude any possible underlying cause for his age. Nevertheless, the TB level increased again with no remaining bile duct stones.

A liver biopsy showed severe bile duct cholestasis and minimal inflammation without any fibrotic change. Based on the exclusion of other potential causes of hyperbilirubinemia and the instances of increased bilirubin occurred after repetitive ERCP, MRCP and liver biopsy, we suggested two possible causes of the prolonged hyperbilirubinemia of this patient. First, the contrast agents gadoterate meglumine and iopromide were suspected to be the causes of the hyperbilirubinemia. Second, the large subcapsular hematoma after percutaneous liver biopsy could be the cause of this hyperbilirubinemia, but it was not severe complication of percutaneous liver biopsy and the drainage was done fast, so it may be minimal effect of this hyperbilirubinemia. The patient was performed conservative management and endoscopic nasal biliary drainage, and bilirubin levels were spontaneously returned to baseline levels after 43 days.

Prolonged hyperbilirubinemia is a rare complication of ERCP and little cases are reported in child age group. ${ }^{2-5}$ The exact mechanism of this complication remains unknown, but it may be associated with iodine contrast agent such as iobitridol or diatrizoate 4 or antibiotics which is one of the cephalosporins used after ERCP to prevent infection. In summary, we report that the contrast agent in ERCP and MRCP may possibly induce prolonged hyperbilirubinemia in children. ${ }^{6}$ In this case, our patient did not receive cephalosporins after ERCP.

The side effects of gadolinium-based contrast agents include nausea, skin rash and vascular edema or anaphylaxis. ${ }^{7}$ A few cases of gadolinium-induced cholestasis have been reported, and a little case in children group. ${ }^{8}$ Therefore, we thought his prolonged hyperbilirubinemia was associated with the contrast agent. Additionally, the interval between the use of contrast agents and bilirubin increases supported this possibility.

Post ERCP hyperbilirubinemia has been reported to resolve after 2-4 months, ${ }^{3}$ although it took approximately 1 year for this patient's bilirubin level to return to baseline levels. It may be related to repetitive use of contrast and its secondary damage.

The general management for hyperbilirubinemia caused by contrast agent is UDCA and cholestyramine can be used to relieve symptoms. If a trial of these two agents are unsuccessful, corticosteroids may be added with or without plamapheresis. ${ }^{9}$ Our patient kept intravenous fluid hydration, fat soluble vitamin supplement, UDCA (200 mg 3 times daily), prednisolone (30 mg once daily), and cholestyramine (4 g 3 times daily) failed to stabilize the bilirubin level, endoscopic nasal biliary drainage was kept. So, we considered plasma exchange to prevent damage to liver cells due to prolonged cholestasis. This patient presented a drug-induced liver injury added to cholecystitis, which presented as prolonged cholestasis after successful cholecystectomy, ERCP for distal CBD stone and MRCP. Right subhepatic hematoma was noted after percutaneous liver biopsy, but it was not a severe complication and it may cause minimal effect of his hyperbilirubinemia. Clinicians should be aware that the contrast agent iopromide and gadoterate for ERCP and MRCP may cause the prolonged hyperbilirubinemia.

\section{요 약}

저자들은 길버트 증후군 환아에서 조영제 사용 후 발생한 지속적 황달 증례를 보고하는 바이다. 이는 비교적 드문 증례로, 임상에서의 꾸준한 관찰이 필요하다.

국문 색인: 조영제; 길버트 증후군; 고빌리루빈혈증; 담석; 소아

\section{Conflicts of Interest}

The authors have no conflicts to disclose. 


\section{REFERENCES}

1. Aiso M, Yagi M, Tanaka A, et al. Gilbert syndrome with concomitant hereditary spherocytosis presenting with moderate unconjugated hyperbilirubinemia. Intern Med 2017;56:661-664.

2. Bale G, Avanthi US, Padaki NR, Sharma M, Duvvur NR, Vishnubhotla VRK. Incidence and risk of gallstone disease in Gilbert's syndrome patients in Indian population. J Clin Exp Hepatol 2018;8:362-366.

3. Tziatzios G, Gkolfakis P, Papanikolaou IS, Dimitriadis G, Triantafyllou K. An unusual case of prolonged post-endoscopic retrograde cholangiopancreatography jaundice. Hepatobiliary Pancreat Dis Int 2016;15:220-222.

4. Dourakis SP, Mayroyannis C, Alexopoulou A, Hadziyannis SJ. Prolonged cholestatic jaundice after endoscopic retrograde cholangiography. Hepatogastroenterology 1997;44:677-680.
5. Chavalitdhamrong D, Donepudi S, Pu L, Draganov PV. Uncommon and rarely reported adverse events of endoscopic retrograde cholangiopancreatography. Dig Endosc 2014;26:15-22.

6. Niriella MA, Kumarasena RS, Dassanayake AS, Pathirana A, de Silva Hewavisenthi J, de Silva HJ. Worsening cholestasis and possible cefuroxime-induced liver injury following "successful" therapeutic endoscopic retrograde cholangiopancreatography for a distal common bile duct stone: a case report. J Med Case Rep 2016;10:371.

7. Ramalho J, Ramalho M, Jay M, Burke LM, Semelka RC. Gadolinium toxicity and treatment. Magn Reson Imaging 2016;34:1394-1398.

8. Elbeshlawi I, AbdelBaki MS. Safety of gadolinium administration in children. Pediatr Neurol 2018;86:27-32

9. Saritas U, Aydin B, Ustundag Y. Plasmapheresis and corticosteroid treatment for persistent jaundice after successful drainage of common bile duct stones by endoscopic retrograde cholangiography. World J Gastroenterol 2007:13:4152-4153. 